\title{
Voluntariado Social en el Siglo XXI: ¿Movimiento Social o Instrumento Neoliberal?
}

\section{Social Volunteerism in the XXI Century: Social Movement or Neoliberal Instrument}

\author{
José Guillermo Fouce Fernández \\ Psicólogos Sin Fronteras Mdrid
}

\begin{abstract}
Resumen. El presente articulo abordará, desde una perspectiva expositiva dialéctica como instrumento pedagógico de comunicación, alguno de los principales debates críticos a establecer con respecto al concepto de voluntariado y su uso desde una doble visión, la neoliberal o como movimiento social transformador. Abordar en las organizaciones sociales debates como el que ahora se presenta resulta necesario para poder clarificar el papel que jugamos las organizaciones y voluntarios en la sociedad que vivimos. Se apuesta por esta concepción crítica del voluntariado para delimitar una opción por el voluntariado como movimiento social transformador.

Palabras clave: voluntariado, participación social, movimientos sociales, neoliberalismo.

Summary. This article will approach from a dialectical perspective, some of the main critical debates to settle down with regard to the volunteerism concept and its use from a double vision, the neoliberal vision versus social movement. To approach in social organizations discussions such the one that now is presented is necessary in order to clarify the role that organizations and volunteers play in the society. It is bet by this critical conception of volunteerism to define an option as a transformer social. Movement.

Key words: volunteerism, social participation, social movements, neoliberalism.
\end{abstract}

"Si la sociedad consagrase al esfuerzo de satisfacer las necesidades básicas de los más pobres siquiera una fracción de las ingeniosidad y los recursos que destina a moldear las preferencias de consumo de quienes tienen poder de comprar, hace mucho que se habrían erradicado la pobreza y el hambre."

Jorge Riechmann (1991)

\section{Introducción}

Cuando un fenómeno social como el voluntariado se eleva a los altares de lo políticamente correcto, de

La correspondencia sobre este artículo puede dirigirse al autor a las siguientes direcciones de correo electrónico guiller@cop.es; psf@psicologossinfronteras.net la moda, de lo aprobado por todos e impulsado por sensibilidades diversas y opuestas: liberales, conservadoras, neoliberales o alter mundistas y progresistas; cuando se ensalza su positividad sin límites y sus elevadas bondades cabe como señala Falcón (1997) entre otros, empezar poniendo en cuestión el término y la realidad a la que responde, sospechar del concepto y su significado.

Complementariamente "cuando todo movimiento social resulta siempre sospechoso al poder- al menos por su espontaneismo y potencialidad de disidenciano deja de causar cierta perplejidad la paradoja de que sea el propio poder el que incentive ciertas formas de dinamización del tejido social a través del voluntariado" (Segovia, 2000).

Si no hacemos este ejercicio de autocrítica corre- 
remos el riesgo de desvirtuar el término y la realidad que intenta manifestar, el mismo perderá sentido en este importante momento de consolidación y maduración del movimiento de voluntariado tras el boom inicial de hace algunos años.

Sólo desde una perspectiva crítica, desde una perspectiva reflexiva y lejana de la auto complacencia podremos avanzar en el desarrollo creciente de una forma de participación que, bien entendida, conlleva sin duda, elementos muy importantes de cambio y transformación social, al tiempo que estilo de vida y forma de ver la realidad, ejercicio de ciudadanía y escuela de participación.

Parece claro por tanto, al menos desde una visión del voluntariado en el marco occidental, que el voluntariado merece ser puesto bajo el paraguas de la crítica y reflexión para delimitar sus usos y prácticas actuales, y más si pensamos en los usos del término que se están dando desde marcos conceptuales o espectros ideológicos opuestos entre sí, como veremos.

Visión del voluntariado que por cierto, no es universal, ni generalizable, pues en el Sur, el voluntariado tiene más que ver en muchos de los casos con fenómenos aún más diferentes, como el desarrollo comunitario o el sostenimiento comunitario ante las crisis de las comunidades afectadas por los reajustes económicos, por la exclusión y la globalización, con el desarrollo de respuestas colectivas de resistencia a veces más explicita y a veces más ligadas a la mera supervivencia que dan los propios afectados y sus aliados, también voluntarios como ellos.

Esté ejercicio crítico no puede ser, por otra parte, un ejercicio retórico, teórico, abstracto... debe servir para que las organizaciones de voluntariado y los voluntarios discutamos, para que establezcamos regulaciones y límites, para que debatamos y nos posicionemos porque en ello nos va la esencia de nuestro pretendido movimiento, la esencia de la transformación, justicia e igualdad y el cambio social por el que supuestamente apostamos.

Cabe señalar además, que las aportaciones y críticas que se van a desarrollar a lo largo del texto no se hacen desde la distancia, desde la torre de marfil de la teoría, sino desde la implicación directa, concreta y continuada del autor en ámbitos relacionados con la intervención social en general y el voluntariado en particular, desde hace mucho tiempo, como voluntario, como dirigente de organizaciones y como formador y acompañador de procesos de creación y desarrollo de entidades y voluntarios/as.

Pues bien, desde este papel múltiple y paradójico que, al tiempo le identifica a uno como voluntario, asociado, directivo, pensador, soñador utópico, ocupa, militante o activista se pretende aportar mediante este texto algunas palabras para el debate y la reflexión en nuestras organizaciones y con nuestros voluntarios/as. Uno se considera voluntario y, por tanto, militante, como plantea Falcón (1997).

\section{Análisis crítico del voluntariado y las ONG}

Aunque quizá una visión dicotómica de la realidad puede establecer algunos sesgos en el análisis de la situación, tiene la ventaja de ser mucho más clarificadora que otras posibilidades de explicación y comprensión por lo que vamos a utilizar este ejercicio de clarificación sin claroscuros como una forma de establecer y delimitar diferencias entre unas visiones y otras aun siendo consciente que ambas visiones y perspectivas se mezclan en la realidad de manera que resulta muchas veces imposible establecer diferenciaciones tan necesarias como complejas de desarrollar.

\section{A) Visión neoliberal, individualista y conservado- ra del voluntariado}

Se desglosarán ahora brevemente, algunas de las interpretaciones neoliberales- conservadoras o individualistas en el ejercicio de la acción voluntaria como instrumentos de interpretación orientada de este fenómeno.

\section{a) Consenso y alabanzas: ¿hablamos de lo mismo?}

Al voluntariado se lo alaba desde la administración pública (regulándolo legislativamente, invirtiendo en planes y profesionales para desarrollarlo, 
invirtiendo en su implantación y desarrollo e incluso creando voluntarios de la propia administración, redes de información y fomento del voluntariado, subvenciones, años internacionales, etc.), desde la empresa privada (y, especialmente, desde los departamentos de marketing adjetivado de solidario, que van creando valores añadidos y buena imagen de sus productos asociándolos a supuestos fines solidarios o sociales asociados a la venta y el producto, a la imagen de marca), desde organismos internacionales como el FMI o el Banco Mundial apuestan por él como forma de desarrollo político y respuesta a los retos que plantea la globalización económica generadora de desigualdades crecientes, desde pensadores situados en el neoliberalismo. También se le alaba desde todo el arco político tanto desde la izquierda, como desde la derecha neocom basada en la caridad- filantropía individual ("con rostro humano”) recuperada, por ejemplo, por Bush y sus acólitos.

Pero ¿todos estos ámbitos tan diferenciados en el resto de cuestiones están hablando del mismo fenómeno? ¿Tienen la misma concepción del voluntariado y los voluntarios-as? ¿Hablan de lo mismo? ¿Tienen los mismos objetivos? Rotundamente, como trataremos de desglosar en el presente texto, no.

Parece claro que no sé esta hablando del mismo fenómeno o que, al menos, hay claras discrepancias $\mathrm{y}$ divergencias entre lo que pretenden decir unos y otros sobre el mismo término por lo que conviene delimitar el terreno y diferenciar desde una perspectiva crítica para no lograr, sin quererlo, desde el desarrollo de nuestras acciones bien-intencionadas objetivos diferentes, incluso opuestos, a los que pretendemos conseguir haciéndoles el juego a propuestas contrarias a las propias.

Hay por tanto diferentes e incluso opuestas visiones y concepciones del voluntariado, podríamos hablar de "voluntariados" más que de voluntariado como fenómeno único o unitario.

Por otra parte nos encontramos el acrónimo ONG, definido por lo que no se es y sin decir demasiado de lo que se pretende ya que no gubernamentales serían, también, estrictamente hablando, desde organizaciones mafiosas, a un banco o una fundación ligada a una multinacional.
Desde el terreno de los movimientos sociales en estos principios del siglo XXI sabemos que uno de los principales debates y conflictos a establecer tiene que ver con la delimitación lingüística y cultural de conceptos y realidades, pues éstos se ven invadidos desde ámbitos claramente en conflicto y con visiones y propuestas diferentes de la realidad. Nos estamos refiriendo, por ejemplo, a la lucha por delimitar la realidad e interpretarla desde el neoliberalismo, utilizando instrumentos y palabras histórica y clásicamente ligadas a las opciones de progreso para, así, descontextualizarlas y utilizarlas en su propio provecho (Melucci, 1989; 1994; 1996). El establecimiento de marcos de lenguaje para la discusión marcaría la realidad, como señala Lakoff (2007) en el conocido ensayo "No pienses en un elefante". Nos estamos refiriendo, por ejemplo, al uso de términos como la libertad, la igualdad o los supuestos derechos humanos ligados a la propiedad que hoy se defienden desde el liberalismo económico radical o neoliberalismo de manera análoga y retorcida: planteando que es un derecho humano de cuarta generación y ligado a la libertad no pagar impuestos.

Se trata de poner como principio ético fundamental la libertad económica, combatiendo y denunciando cualquier expropiación total o parcial de la misma (impuestos por ejemplo) por parte de nadie y menos por parte del estado, siendo estas expropiaciones o impuestos declarados como inmorales, agresiones institucionales en contra del libre ejercicio dela acción humana... el socialismo sería un error intelectual. (Huerta de Soto, 1996).

Otra pista de que posiblemente no nos estemos refiriendo a lo mismo tiene que ver con los términos que usamos para definir la realidad, cuando todos hablamos de voluntariado como supuesto fenómeno unitario y general, cabría quizá plantear las diferencias conceptuales y de contenido entre términos como voluntario, militante, asociado, ocupa, activista, etc.

Cabría preguntarse por qué a unas figuras de participación (los voluntarios) se les concede legitimidad y legitimación, impulso (también mediático o de buena imagen social-moda), inversión (subvenciones variadas, por ejemplo) y consenso y a otras se las aparta en el camino.

¿Acaso no hablamos de las mismas realidades en 
las que las personas dan una parte de su tiempo poniéndose a disposición de la comunidad, promoviendo sus ideas y su forma de entender la solidaridad desde un grupo u organización? ¿Por qué entonces parece preferirse el voluntario al militante $\mathrm{o}$ al asociado? ¿Cuál es la diferencia entre uno y otro? ¿En qué se diferencias un militante político, una feminista, un ecologista, un pacifista, un ocupa, de un voluntario?

Cabe preguntarse ¿por qué personas que también desarrollan otro tipo de acciones de voluntariado como los defensores de los derechos humanos en países de América del Sur o los participantes en movimientos críticos como el mal llamado de la anti globalización (más bien movimiento alter mundista o por una verdadera globalización, la de los derechos humanos) han sido y son perseguidos por las autoridades, mientras que el voluntariado es alabado y potenciado? (Madrid, 1999). Estas personas también desarrollan una actividad voluntaria pero las consecuencias y la visión social sobre sus acciones, sobre su actividad es desincentivarla cuando no reprimirla, impedirla y perseguirla.

Los movimientos sociales suelen ser contrapoderes (Touraine, 1997) que tratan de construir las personas con sus actuaciones, que solicitan una distribución de los recursos existentes, siempre escasos, guiándose por otros valores e ideas, los poderes estatales históricamente desconfían de ellos y se les oponen ya que constituyen una amenaza al orden económico, social y político. ¿Qué modelo de voluntariado o que tipo de voluntario es el apoyado y fomentado y por qué? ¿Es el primer movimiento social apoyado por lo estatal y establecido?

\section{b) Funcionales para el sistema, amortiguadores de conflictos, generadores de confianza}

El voluntariado y las organizaciones de voluntariado serían funcionales para el sistema, útiles para responder a algunos retos del mismo como la necesaria respuesta hacia los "nadies" (en palabras de Galeano), los excluidos, los excedentes en el reparto de la riqueza.

Los voluntarios, desde su acción poco reflexiva, individual e individualista ejercerían de frenos del sistema, de frenos ante posibles cambios sociales o sociopolíticos (léase también revoluciones), generarían confianza en el sistema (en términos usados por Fukuyama $^{1}$, 1992, 1998, 2005 entre otros) y mantendrían las cosas en su sitio, sin rupturas, minimizando las protestas y resistencias, para que todo siguiese igual y la maquina de la economía mundial depredadora y generadora de desigualdad pudiese seguir triturando personas y realidades.

Francis Fukuyama, (1952-actualidad) defensor del neoliberalismo y su conocida tesis del fin de la historia por estar en el mejor de los mundos posibles, defiende con fuerza la necesidad de favorecer la constitución de un cuerpo de voluntarios que sostengan y respondan a las inherentes e inevitables consecuencias negativas en forma de desigualdades severas que genera el capitalismo globalizado, voluntarios que, además, sean los frenos de seguridad del sistema y que supondrían, al tiempo, confianza y afianzamiento del mismo.

El voluntariado seria una estructura de mediación y contención como las organizaciones religiosas, por ejemplo, el voluntariado sería valorado y valorable (por ejemplo, para conceder fondos del Banco Mundial o el FMI a los países en crisis o para aprobar planes de ajuste) como garantía de vitalidad y supervivencia de las instituciones políticas y económicas neoliberales (Fukuyama, 2005) y sus planes de ajuste reforzando el mercado y haciéndole escasamente regulable.

La explosión de las ONG y el voluntariado coincide con la creciente hegemonía neoliberal a escala planetaria y, en ningún caso parece preocupar a ningún organismo, institución o empresa representantes del Nuevo Orden Mundial globalizado. Por el contrario no parecen existir dudas para ningún posicionamiento ideológico de la bondad del fenómeno y la necesidad de promocionarlo, invertir en él, potenciarlo.

Las ONG son funcionales y cumplen una misión positiva para el sistema: "las ONGs tienen un importante papel que jugar en la rearticulación social que necesita el modelo neoliberal: paliar los costes de las políticas neoliberales atendiendo a los casos más extremos, canalizar la reivindicación social vía par-

\footnotetext{
${ }^{1}$ No hay que olvidar que Fukuyama fue asesor del gobierno americano en tiempos del más rígido neoliberalismo y que se le conoce como el creador de la tesis del fin de la historia.
} 
ticipación solidaria y generar consenso con relación a la universalidad y naturalidad del orden económico. La seguridad y la estabilidad social son imprescindibles para asegurar el correcto funcionamiento del proceso de acumulación y las ONGS junto a otras organizaciones sociales pueden contribuir a esa estabilidad" (Díez, 1999).

Ahora sí se reconoce que las políticas de ajustes generan problemas y hay que dar repuesta a los mismos: "Ya a principios de los 80 , los sectores más perceptivos de las clases dominantes neoliberales se dieron cuenta de que sus políticas estaban polarizando a la sociedad y provocando descontento social a gran escala...(por ello) comenzaron a financiar y promover una estrategia paralela "desde abajo": la promoción de organizaciones "de base" de ideología "anti-estatista" para intervenir entre las clases potencialmente conflictivas, para crear un "colchón social" (Petras, 2006).

Así que, una parte al menos, del boom de las ONG tendría que ver con un planteamiento pensado y dirigido desde las cúpulas del neoliberalismo (FMI; Banco Mundial, empresas transnacionales, pensadores neoliberales o neocom etc.) con algunos elementos comunes: el desmontaje del Estado, paliar las consecuencias negativas de su modelo económico sin que este cambie, generar confianza en el sistema por parte de la sociedad civil.

El voluntariado sería una fuente inagotable de presión hacia la privatización de servicios desde la máxima establecida de que la mejor empresa pública es la que no existe y la mejor inversión social la que no cuesta y se genera por la respuesta colectiva.

Se trata de socavar al estado con una estrategia dual, en pinza y, al tiempo, compensar a las víctimas del sistema neoliberal, amortiguar los golpes, proporcionando servicios sociales asistencialistas, caritativos y que se proporcionan no por derechos sociales o por ser justos sino por caridad. Además, estas soluciones serían más baratas, más eficientes y con importantes valores añadidos en la sociedad de mercado, de la imagen: descontar impuestos, hacer marketing solidario, generar buena imagen, tener satisfechos y entretenidos al tercio de la sociedad que no siendo excluida esta en riesgo de serlo o solo sobrevive.

Las ONG se convirtieron así, en la "cara comunitaria" del neoliberalismo completando el trabajo destructivo del mismo en proyectos locales (Petras, 2006).

Se pretende apuntalar la visión positiva y acrítica del voluntariado como movimiento, reconociendo la labor de los voluntarios-as y estableciendo marcos potenciadores de este tipo de acción social, impidiéndole cambio o la transformación social, huyendo o rehuyendo del estado o de la política, de preguntarse por las causas, por los porques, de la reflexión, no se pueden generalizar las reflexiones o preguntas, poner en común al inmigrante con los inmigrantes, el excluido con los excluidos y la exclusión, se huye o rehuye del estado o de la política.

Por otra parte, "el asociacionismo no solo es bueno para la política, sino también para la economía: las asociaciones inculcan el hábito de trabajar en equipo con facilidad y, por tanto, incrementan la productividad; hacen innecesarias las reglas rígidas y los complejos contratos legales. En pocas palabras suavizan las fricciones del capitalismo" Fukuyama (2005).

Podemos también conectar con la clásica disyuntiva o dilema ético planteado a muchas ONG: ¿intervenimos en una situación de exclusión respondiendo a las necesidades de la gente que sufre y así le hacemos el juego a los causantes de las situaciones? O dicho de otra manera: ¿hasta que punto si intervenimos en la realidad dando respuestas estaremos evitando que las situaciones "exploten" y se produzca la revolución, la transformación, el verdadero cambio en las estructuras?

Al responder a la precariedad y la exclusión estaríamos haciéndole el juego al sistema, y por tanto, seriamos necesarios y útiles, evitaríamos la explosión social, la revolución, poniéndole frenos a la explotación, paliando sus consecuencias para que nada de lo fundamental cambiase. Un juego perverso, complejo y difícil, que tiene una fuerte carga de dilemas éticos complejos de resolver asociados al mismo.

\section{c) Mantener ocupados y contentos a los exceden- tes. Empleabilidad y privatización servicios}

El voluntariado puede servir para que, por ejemplo, los jóvenes mileuristas que trabajan en precario, lejos 
de su vocación y de su formación o las mujeres excedentes del mercado laboral (dígase también, por ejemplo, amas de casa) o personas mayores con tiempo libre, por ejemplo, con jubilaciones anticipadas, encuentren algo que hacer y con lo que sentirse bien mediante el desarrollo de acciones voluntarias, cubriendo, en parte, sus necesidades y así acallados en su malestar alienante potencialmente destructivo en lo personal y movilizador en lo colectivo y en lo político.

Otra trampa sería la utilización perversa de la retórica de la responsabilidad compartida entre el Estado y la sociedad para satisfacer intereses generales. Ser responsable es tener que responder y quien por imperativo legal, constitucional, tiene que responder y promover las condiciones para que la libertad y la igualdad del individuo y los grupos en que se integra sean reales y efectivas o para remover los obstáculos que impidan o dificulten su plenitud son los poderes públicos. Participar en la gestión no es tener responsabilidad, son conceptos diferentes. Esta sería una forma más en las que "voluntariado, ONGs y otras formas benévolas poco avisadas no son sino herramientas en un intento de pacífica involución del estado de bienestar hacia uno "moderno" de corte neto neoliberal" (Segovia, 2000).

El voluntariado sería también un campo para ejercer la práctica laboral, para la inserción profesional, para foguearse en el mercado de trabajo. El voluntariado sería la forma en que gran parte de nuevos profesionales se acercarían a su inserción al mercado laboral, sería una de las estrategias de los jóvenes para insertarse (Callejo,1999), un espacio de transición hacia la inserción (Velloso, 1999).

El voluntariado desarrollaría, además, nuevos yacimientos de empleo, como los denominó la Comunidad Europea, nuevas fuentes de empleabilidad (Chacón, 1999).

Las instituciones reconocerían la funcionalidad del voluntariado en la formación de los jóvenes y su inserción (por ejemplo, en el documento que acompañó a la propuesta no de ley 162/249 del parlamento o en el servicio de voluntariado europeo) lo que llevaría a su fomento como proceso, se trataría de proporcionar a los jóvenes una experiencia educativa no formal, de interés para su futuro personal y profesional. Los voluntarios adquirirían hábitos, habilidades situándose en mejores condiciones de ser empleados. Lo cual, si bien puede ser cierto, no puede ser tomado como elemento sustantivo para impulsar el desarrollo de acciones voluntarias.

El voluntariado seria un sector complementario, cuando no sustitutivo, de la acción estatal pública contribuyendo a la precarización de salarios y al establecimiento de condiciones laborales a la baja en el ámbito de los servicios públicos en general y los servicios de intervención social en particular, se sustituirían trabajadores por voluntarios, se sustituirían acciones públicas por acciones privatizadas desde el marco de las ONG.

El voluntariado, serviría para fragmentar, para desunir, para departamentalizar, para que a un sector de la población excluida no entrase en contacto o le importase otro sector, otra problemática u otra población, el que trabaja con drogadictos le es ajeno el 0,7 , el que lo hace con mayores, no quiere saber nada de menores en riesgo. Además las entidades promotoras del voluntariado y sus voluntarios competirían sin freno por recursos escasos.

Sin embargo: "en la aldea global tenemos que universalizar valores solidarios desde los excluidos de aquí y de allá, náufragos todos de un mismo barco que fondeado en las aguas del pensamiento único neoliberal amenaza a todos por igual". (Segovia, 2000). "Debemos arrojar a los océanos del tiempo una botella de náufragos siderales, para que el universo sepa de nosotros lo que no han de contar las cucarachas que nos sobrevivirán: que aquí existió un mundo donde prevaleció el sufrimiento y la injusticia, pero donde conocimos el amor y donde fuimos capaces de imaginar la felicidad". (Gabriel García Márquez, 2002).

El voluntariado se define de acuerdo al parámetro de una relación laboral salvo en la ausencia de remuneración (como hace la misma Ley de voluntariado que establece una relación voluntario-organización muy similar a la relación salarial clásica. El voluntario debe cumplir sus compromisos (realizar su actividad) de forma diligente, ofrecer servicios de calidad y hacerlo siguiendo las instrucciones y la formación que le proporcione la organización. Tiene como en aquella, derechos: a la formación (entendida como obligación y derecho) a la seguridad en el trabajo y al aseguramiento contra los riesgos en el desarrollo de su actividad y al respeto y reconocimiento por su con- 
tribución; además su actividad ha de llevarse a cabo en el marco de una organización y en programas o proyectos concretos en actividades de interés general.

Los voluntarios serían sometidos a auténticos procesos de selección de personal, los puestos de voluntariado se ofrecerían en los mismos espacios que los puestos laborales (Sección de empleo de ABC, Nuevo Empleo, por ejemplo).

En el terreno motivacional lo dicho se traduciría (Velloso, 1999) en que las difíciles aspiraciones personales de encontrar empleo (o de encontrar un empleo satisfactorio en lo personal y en sus condiciones) en un contexto de crisis del empleo llevan a participar como voluntario/a, se aspira a un puesto de trabajo en el futuro mediante el ingreso y participación continua y prolongada en una asociación como voluntario/a.

El Estado tiende a la liberalización y privatización de sus estructuras, la defensa de intereses y necesidades sociales se deja en manos de la iniciativa privada: la sociedad civil se muestra complementaria al proceso de reducción del Estado porque "no hay nada como promocionar la solidaridad para tenerla bajo control" (Velloso, 1999).

Cabe vincular la crisis del Estado de bienestar y el resurgir del voluntariado, lo que en realidad se estaría pretendiendo con el fomento del voluntariado por parte de la Administración pública sería paliar la reducción paulatina de estructuras y presupuestos públicos destinados a la política social. (Madrid, 1999). Para reducir el gasto público se desarrollan modelos alternativos de sistemas públicos de prestación indirecta de servicios. Se trata de una forma relativamente barata de traspasarle a la sociedad civil responsabilidades que afrontadas institucionalmente tendrían un coste no aceptado por todas las instancias defensoras de la ortodoxia económica y la austeridad presupuestaria reinante (Alonso, 1999). Si las cosas son más baratas desarrolladas desde las ONG que lo hagan ellas, por otra parte así se mantienen redes clientelares y la dependencia de los colectivos y organizaciones del Estado y la administración.

\section{d) Marketing solidario y utilización por el mercado}

Con el voluntariado, con la solidaridad, podría- mos no solo acallar nuestra conciencia y culpabilidad por sentirnos responsables sino, además, enmarcar los productos que se pretende colocar en el mercado con un halo de valor añadido, de función social, de buena imagen.

Vuelve a introducirse la caridad, la acción social consiste en la donación graciosa al marginado, al excluido: tiempo, esfuerzos y atención, caridad sin el desarrollo de una perspectiva de justicia social, de derecho del otro a recibir apoyo y respuestas, de solidaridad, de cambio social. Desde esta óptica, si el otro rechaza o cuestiona o quiere participar en nuestra generosa aportación, entonces es, además culpado doblemente de su situación por desagradecido.

Algo que ya ocurría antes, en los tiempos de la "sopa boba", en los tiempos de los servicios de asistencia caritativa, en los espacios precursores de nuestro actual estado del bienestar que reconoce derechos, que da prestaciones y servicios a los ciudadanos porque lo merecen en justicia, no de manera graciable o caritativa.

A veces las ONG se convierten más en "sinónimo de lucro" que "sin animo de lucro".

Ejemplos de esta colonización serían, por ejemplo, la venta de productos verdes o las campañas de marketing y generación de imágenes corporativas utilizando el concepto solidaridad. Se trata de trivializar y comercializar con la solidaridad. Se trata, a veces, de proponer ser solidarios consumiendo más.

Otro tipo de ejemplos, tiene que ver con la adopción por parte de las propias entidades de voluntariado (ONG) de criterios y principios meramente pragmáticos y corporativos. Se trataría de competir, de ser eficaces a toda costa, de guiarse por la racionalidad burocrática y competitiva.

Igual que lo político se convierte en un mercado (oferta de partidos y demanda de los electores) lo social se articula como un mercado (oferta de organizaciones, demanda de los individuos solidarios) (Díez, 1999). La libertad es el principio que rige ambos mercados: cualquier oferta u opción es válida. Las etiquetas no son ideológicas o de valores, sino de especialización. Las opciones son intercambiables y solo se evalúan tecnocráticamente por sus resultados. Los valores, los principios, no existen o son intercambiables, no son relevantes; las reflexiones no son necesarias, ni se potencian, basta con la acción. 


\section{e) Ética indolora, voluntariado individualista, islas de humanidad}

La acción voluntaria debe situarse no en el terreno de la crítica social, lo colectivo, el cambio socio político y de valores, la comunidad o la política sino en el terreno de la voluntad individual, del hedonismo, de la filantropía ejercida desde la libertad individualista, indolora, personalista, no colectiva. Es el desarrollo, por ejemplo, de sindicatos unipersonales o de las acciones filantrópicas según se denominan en los Estados Unidos, el capitalismo con rostro humano de los republicanos.

Para lo mismo, se necesita desarrollar un voluntariado guiado por el individualismo, por un altruismo/ética indolora postmoderno o post moralista como señala, entre otros, Lipovetsky "la cultura cotidiana ya no esta irrigada por los imperativos hiperbólicos del deber sino por el bienestar y la dinámica de los derechos subjetivos; hemos dejado de reconocer la obligación de unirnos a algo que no seamos nosotros mismos".

El voluntariado consistiría en el desarrollo de islas o islotes de humanidad en el seno de sociedades frías y agresivas, invisibles, insufribles, para evitar la ruptura social y cultural; una respuesta a las constantes amenazas de anomia, de falta de hogar a la que los ciudadanos de nuestras modernas sociedades se ven abocados.

Así, coherentemente con el individualismo en el que nos encontramos inmersos, el desarrollo de acciones voluntarias se verá invadido por aspectos procedentes del mismo. La solidaridad se fragmenta, vuelve la caridad sin más, al asistencialismo, la acción voluntaria viene guiada por una adaptación débil y postmoderna en la que derechos y deberes no quedan igualados y obligados por leyes efectivas, sino por percepciones o adhesiones inestables y segmentadas, emocionales, las dimensiones colectivas y las reivindicaciones, la política quedan aparcadas. Los compromisos, adhesiones y consensos son básicamente sentimentales, las acciones parciales o de corto alcance, resulta imposible desarrollar transformaciones o reflexiones generales, globales y críticas; es la vuelta del moralismo pietista.

La solidaridad (o el asistencialismo caritativo, mejor dicho) se desarrolla a tiempo parcial, en el tiempo libre, por mera apetencia personal, las personas se muestran insolidarias el resto de sus vidas, (Velloso,1999). Aparecen los voluntarios epidérmicos, los "apaga fuegos" o "tapa agujeros" (Falcón, 1997), e incluso, los voluntarios "nazis" (dicese de aquellos voluntarios que al trabajar con por ejemplo, inmigrantes, señalan como la situación del inmigrante concreto que conocen y con el que están trabajando es comprensible pero que al hablar de sus actitudes generales ante los inmigrantes expresan actitudes claramente racistas).

\section{Visión progresista, colectiva y alternativa del voluntariado}

"Aprendimos a enamorarnos de la luna, pero no supimos enamorarnos de los rostros tan cercanos, aprendimos a imaginar el futuro según convenía al capitalismo industrial como riqueza de las naciones, pero no supimos imaginarla como una civilización del amor" (García Roca, 1994).

El voluntariado pasa a ser concebido dentro del arco de los movimientos sociales, de los movimientos de resistencia, pasa a tener, por tanto, una inexcusable dimensión política y crítica, dimensión de cambio social, de reivindicación, de acción colectiva y generalizadora, de lucha por los derechos sociales y por el cambio de estructuras desde la acción concreta.

El voluntariado se convierte en una actividad no extraordinaria sino dentro de la vida diaria de las personas, se trata de convertir las acciones de voluntariado en estilos de vida solidarios, pasar al riego sanguíneo, a nuestra vida cotidiana el ejercicio de la solidaridad, se trata de integrar la solidaridad en nuestras vidas de manera incondicional en un viaje de ida y vuelta que nos lleva de la caridad, de conmovernos y emocionarnos mediante el encuentro con el otro, el excluido, la indignación ética por descubrir esta situación, las preguntas sobre los porques, hasta nuestra propia transformación personal y de nuestro estilo de vida o nuestras elecciones como señalan entre otros García Roca (1994) o Falcón (1997).

Como diría Bertold Brecht o cantaría Silvio Rodríguez: "Hay hombres que luchan un día y son buenos. Hay otros que luchan un año y son mejores. 
Hay quienes luchan muchos años y son muy buenos. Pero hay los que luchan toda la vida: esos son los imprescindibles".

El voluntariado, los voluntarios darían la voz a los nadies, mirarían a los márgenes del camino, donde quedan tendidas las víctimas del sistema, los excluidos y revindicaría justicia y dignidad para ellos, se identificaría con la pregunta y respuesta de Neruda "¿Quiénes son los que sufren? No sé pero son míos". Para ello, nos dejaríamos afectar por los excluidos, por sus historias de vida, que irrumpirían en nuestra realidad cotidiana transformándola sin remedio. Desde el encuentro cara a cara, el ejercicio del voluntariado permitiría rasgar el velo de invisibilidad que acompaña las grandes cifras, le pondría voz y rostro a los que sufren y desde el compromiso con los que sufren, apostaría por el cambio social, por la construcción de espacios de vida diferentes, ejemplos de resistencia, ejemplos de otro mundo posible y necesario hecho realidad en el día a día, en la práctica real.

Se trataría de un moviendo ético, cultural, de cambio de valores, pre- político en este sentido, que impediría justificar la injusticia a la que están sometidas miles de personas, millones si adoptamos una perspectiva universal. Se trataría de actuar al tiempo que se denuncia y proponer cambios para tratar de remover las condiciones que llevan a la desigualdad, revindicar la dimensión política (pese a lo, a veces, proscrito de la palabra o su falsa identificación con lo partidista o con los partidos) de la acción social, del voluntariado.

Se trataría de unirnos a otros para participar en lo común, lo que significa hacer política. Porque "quien no hace política, hace pasivamente la política del poder establecido". E. Mounier y "Si me desentiendo de la sociedad humana de la que formo parte, seré tan prudente como quién yendo en un avión gobernado por un piloto completamente borracho, bajo la amenaza de un secuestrador loco armado con una bomba, viendo como falla uno de los motores, en lugar de unirse con los restantes pasajeros sobrios y cuerdos para intentar salvarse, se dedicara a silbar mirando por la ventana o reclamara a la azafata la bandeja del almuerzo" (Savater, 1995).

Seria una acción cercana, concreta, desde lo local hacia lo global, ejercicio de ciudadanía universal en el que todo ser humano es radicalmente igual, con los mismos derechos y deberes, en el que todas las personas pasan a ser de nuestra incumbencia, sin excluir a nadie. Somos humanos gracias a los otros, ejercemos y construimos nuestra humanidad con los otros.

El ejercicio del voluntariado debe ser un dique frente a la ceguera y la indiferencia, frente al individualismo egoísta. La acción voluntaria es una escuela de los ojos abiertos, del mirar detrás y mas lejos. La solidaridad no mira desde cualquier sitio, sino desde los últimos, no es la mirada del astronauta que ve la tierra como una pelota colorada, sino la mirada que huele y oye, siente y se deja afectar (García Roca, 1994) porque las cosas son sin duda como señala Benedetti según el dolor con que se las mire. El voluntariado establecería formas de vida guiadas por valores alternativos, un freno y contrapeso a la cultura del consumismo, del materialismo e individualismo, guiado por la gratuidad, por el encuentro con el otro o por el establecimiento de procesos colectivos.

Se trata de un movimiento que rompe fronteras, basado en la concepción de que cualquier ser humano tiene los mismos derechos sin exclusión que el resto de la humanidad. Se trataría de apostar por la globalización de los derechos, de los derechos humanos.

Se trata de un moviendo generador de zonas liberadas en el seno de la sociedad actual, islotes que escapen a la lógica mercantil, al cálculo económico y las necesidad económicas urgentes y, también, del Estado. Espacios en los que se manifieste la posibilidad de desarrollar otro estilo de vida, nichos ecológicos en los que puedan sembrarse y crecer alternativas culturales y de valores a la sociedad del tener y el individualismo, a la ética indolora, al egoísmo acaparador y devorador. Islotes que tienen además que conectarse, interconectarse, desde su diversidad y pluralidad, vista ahora como potencialidad y valor positivo mas que como elemento negativo.

"Somos diversos... la diversidad es nuestra fuerza y su expresión es la base de nuestra unidad. Somos un movimiento de solidaridad global, unido en nuestra determinación de luchas contra la concentración de la riqueza y la proliferación de la 
pobreza y la destrucción de nuestro planeta" (declaración final Foro social mundial 2002).

Es mostrar en la práctica que otro mundo es posible, otras formas de vivir, desarrollar alternativas emancipatorias desde la practica cotidiana (Zubero, 2006).

Como señala Riechmann (1994) "no necesitamos vanguardias omniscientes, pero en cambio son inexcusables las minorías ejemplares", los buenos ejemplos que rompan el uniformismo individualista y generador de diferencias de nuestras sociedades actuales.

Se trata de una tarea, un movimiento de resistencia en red, necesariamente conectado con otras resistencias.

Una tarea de conexión: "Juntos haremos triunfar el amor. En esa dura batalla, en la que se esta decidiendo el futuro de tantas y tantos hermanos, se decidirá también el nuestro. Estoy seguro de encontrarte en cualquier esquina, aportando tu esperanza y tu energía y en el mismo inmenso bando. El bando del amor armado...tenemos que armar el amor para que florezcan obstinadas primaveras. Para que no logren vencer los que quisieran un invierno eterno para la libertad de nuestras mentes y nuestras emociones", (Mendilulce, 1997).

Una tarea que conllevará en no pocas ocasiones, retrocesos, fracasos o desánimos ante los que debemos adoptar una visión positiva. en la línea de lo que señala Galeano (1993) por ejemplo: «Ocurrió en el tiempo de las noches largas y los vientos de hielo: una mañana floreció el jazmín del Cabo en el jardín de mi casa y el aire frío se impregnó de su aroma, y ese día también floreció el ciruelo y despertaron las tortugas. Fue un error y poco duró. Pero gracias al error, el jazmín, el ciruelo y las tortugas pudieron creer que alguna vez se acabará el invierno. Y yo también.»

Por otra parte, hay que reflexionar en profundidad sobre los derechos humanos para hacerlos transculturales y colectivos así como para introducir nuevos derechos no originalmente concebidos y hay también, que reflexionar seriamente sobre nuestro modelo de desarrollo y el significado real que supone descubrir que hay límites al desarrollo, que hay escasez de recursos y resulta imposible extender nuestro modelo de desarrollo a todo el mundo, que no hay recursos para todos, no vaya a ser que los derechos reconocidos por todos no puedan serlo y sean, más bien, privilegios de unos pocos. "En estas condiciones y por decirlo provocadoramente hoy la solidaridad nos obliga a renunciar a disfrutar de algunos derechos" (Zubero, 2000). La izquierda debe poner en pie una coalición que apele a la solidaridad del mayor número posible de fuertes con los débiles en contra de sus propios intereses.

Hay hoy que reinventar la economía, el modelo de desarrollo, crear una nueva economía ecológica de mercado, de desarrollo sostenible, un nuevo pacto eco-keynesiano que cambie nuestro modelo de desarrollo y consumo, consumir menos para vivir mejor. Se trata, además, de configurar y desarrollar una verdadera ciudadanía universal, sin fronteras, justa e igualitaria al tiempo que reconoce y respeta las diferencias (Zubero, 2006).

Un nuevo mundo sin guerras, que seguirán existiendo mientras allá fronteras "Porque las guerras continuarán existiendo mientras el color de la piel sea más importante que el de los ojos". Bob Marley o como diría Víctor Hugo: "Tened por patria el mundo y por nación la humanidad"

El gran drama de nuestro mundo moderno tal como hoy esta construido, bajo la hegemonía del neolibelismo, es que un gran número de personas, un gran número de países no son necesarios ni para ser explotados, son simplemente sobrantes, excluidos del sistema, no tiene nada con lo que participar en el juego.

Los voluntarios, el voluntariado, debe volver a resituar a los excluidos en el centro del sistema, para movilizar políticamente su sufrimiento y conseguir la reasignación de recursos, con la dificultad que supone que los mismos no votan y los que lo hacen, la clase media, solo reclaman hoy seguridad y poco más, no reformas o cambio social.

A veces, surgen debates y dudas en el seno de las organizaciones sobre si somos o debemos ser movimientos sociales, para aclarar alguno de los debates, conviene recordar lo que es un movimiento social: (siguiendo a Touraine) acciones colectivas que apuntan a modificar la forma de utilización social de recursos importantes en nombre de orientaciones culturales aceptadas en la sociedad.

El voluntariado desde esta perspectiva crítica, 
concebido como movimiento social, desarrolla su acción ensanchando el espacio de visión, con una tarea pre- política, permitiendo lecturas y visiones de la realidad distintas a las habituales, ejercicios de valores diferentes, de estilos de vida distintos. Es una tarea centrada en ampliar el repertorio y marco de valores en la sociedad para construir la protesta, es la generación de nuevos espacios culturales, la cultura de la solidaridad. Se trata de cuestionar la realidad aceptada y configurar marcos de actuación y valoración diferentes.

Se trata de soñar y recuperar la utopía: "dichosos vosotros que soñáis y lucháis, porqué corréis el dulce riesgo de ver realizados vuestros sueños" Helder Cámara porque como canta Manu Chao "La resignación es un suicidio permanente" Y solo los peces muertos siguen la corriente

Debemos, mediante el debate y el trabajo en red, configurar marcos de protesta que legitimen las protestas, las resistencias, que las hagan entendibles, que sean compartidas por muchas organizaciones y ciudadanos, que hagan al tiempo soñable y viable un mundo diferente y posible (Klanderman, Zubero, Melucci).

Todo lo cual solo puede hacerse desde la indignación ética, desde la rabia canalizada: "Rabia es la sangre que hierve por conseguir las metas de nuestra indignación rabia es el arte, la lucha por la libertad la hoguera en los barrios de lo sin dios rabia es el semblante de los oprimidos es un fruto de la noconformidad. Si hay certeza de que esto debe estallar rabia es lo que falta... Rabia es sentarse frente al televisor sintiendo que alguien te oculta la realidad rabia es el arma de los olvidados el instinto del eterno perdedor rabia es contrario a desidia y derrota es la puerta que no se debe cerrar. Rabia es coraje y desesperación es el cambio, la ruptura y la solidaridad. (Reincidentes "rabia").

Todo lo cual supone construir también nuevos espacios públicos, nuevos espacios de resistencia, basados en el día a día y comprobables y visibles como ejemplo palmario de otra realidad posible, hacer pedagogía con las demostraciones prácticas, minorías ejemplares, más que elites conductoras e interpretadoras, vanguardias del proletariado.

Se trata de desarrollar en la práctica modelos de vida diferentes, solidarios, sin aplazarlos hasta des- pués de la revolución, solidarizarse con las personas, empatizar.

Debemos ponernos en marcha, actuar, porque solo actuando podemos cambiar las cosas: "Son cosas chiquitas. No acaban con la pobreza, no nos sacan del subdesarrollo, no socializan los medios de producción y de cambio, no expropian las cuevas de Ali Baba. Pero quizás desencadenen la alegría de hacer y la traduzcan en actos. Y al fin y al cabo, actuar sobre la realidad y cambiarla, aunque sea un poquito, es la única manera de probar que la realidad es transformable.... Al fin y al cabo, somos lo que hacemos para cambiar lo que somos." (Galeano, 1992).

Es un ejercicio de solidaridad, por cierto, sin fronteras, en el que todos los seres humanos son iguales, recuperando el viejo sueño del reconocimiento incondicionado, de la común e igual dignidad de todas las personas, la fraternidad universal, la solidaridad innegociable, la justicia para todos. Es, apostar porque ningún humano pueda ser privado de sus derechos como persona sin hacer depender, por supuesto, esta consideración de fronteras nacionales o de ser considerado extranjero.

Es construir un mundo habitable no solo para los más fuertes, un mundo en que quepan muchos mundos.

El voluntariado seria una fuente de cohesión social al reconocer al otro como humano, como cercano como alguien que merece nuestra cercanía desde lo cotidiano y el encuentro (Zubero, 2006). Con rasgos como la vecindad o el logro de una sociedad incluyente como distintivos. Hablar, relacionarse, empatizar, aceptarnos los unos a los otros recíprocamente, reconocer al otro vinculado a mi.

Se trataría de generar vínculos, comunidades, vecindad frente a la vida de hoy vivida con frecuencia "sin vecinos" y sin comunidades, frenar la producción social de la distancia, de la indiferencia moral, la construcción política del extraño (fuentes por otra parte de muchas de las situaciones de limpieza étnica en la historia), frente al corto plazo "nada a largo plazo" del capitalismo o el final de los vínculos (solo superficiales, de usar y tirar), de la cultura instrumental hedonista e individualista o las relaciones solo por el beneficio.

El voluntariado seria una fábrica de generar vin- 
culaciones sociales, seria deposito de humanidad, de solidaridad y debería desarrollarse desde lo local, desde el día a día, desde lo cotidiano y lo concreto. Es ejercicio de la ciudadanía y de desarrollo comunitario.

Apostamos por una visión del voluntariado como movimiento social, crítico por tanto con el sistema, molesto al mismo, despertador de conciencias y de resistencias, una visión que defiende al voluntariado como una opción crítica con el entorno social donde se enmarca, que habla de su capacidad transformadora para con la vida del sujeto y para con las estructuras sociales, que defiende el ejercicio de la solidaridad ligada a derechos y a la justicia social frente a la caridad asistencialita que considera al excluido como inferior, que aboga por plantear las causas últimas de los problemas sociales, por la reflexión crítica y global desde lo cercano, por la independencia con respecto al Estado y al Mercado.

Una visión, que enmarca al voluntariado dentro de márgenes más extensos y que gusta más de hablar de todo tipo de acciones voluntarias: desde las que desarrollan militantes políticos hasta las iniciativas de asociacionismo, porque considera que las mismas pueden generar más estructuración y capacidad de crítica y cambio; una visión que trata de centrar o atender aspectos controvertibles y cuestionadores tanto para los responsables de gestionar acciones de voluntariado como para los propios voluntarios.

Una visión, que trata de abrir nuevos cauces de discusión y debate en torno a ese nuevo espacio de participación ciudadana que es hoy el voluntariado social, para tratar de colaborar en su potenciación y profundización crítica, para tratar de mejorarlo y llenarlo de un contenido potente, crítico y transformador.

Necesitamos que el voluntariado sea un sector de actividad pública con voluntad de mantener capacidad crítica con respecto a los poderes económicos y estatales y no un simple brazo ejecutor o extensión humanizada de las administraciones o un adecentador solidario de las empresas privadas. Tampoco puede significar la reproducción de estructuras benéfico- asistenciales que creíamos superadas. Hay una importante dimensión política y crítica a despertar.

Los ciudadanos, mediante su compromiso concreto y tangible, voluntario, muchas veces asisten- cial, deben convertirse en agentes del cambio necesario, mediante el pensamiento, la reflexión y la creación de organizaciones, comunidades y unidades, por tanto, con dimensión inexcusablemente política.

Hay que centrar el voluntariado en la tensión o conflicto que genera, que late o debería latir bajo el desarrollo de estas acciones, la independencia con respecto a las administraciones, o el voluntariado como forma de vida más allá de ser una actividad concreta y específica, que cala y transforma lo personal, lo cotidiano y que desde ahí transforma y tiende a transformar lo social, voluntariado que inquieta y desafía lo existente, que busca el cambio y que genera malestar y conflicto, dicho de otro modo es la solidaridad frente al asistencialismo.

Porque "por una parte debo de cambiar el alma de los individuos para que sus sociedades puedan cambiar. Por la otra, debo tratar de cambiar las sociedades de manera que el alma individual tenga una oportunidad". (Martín Luther King).

El presente texto se escribe como reflexión crítica basada en la experiencia directa y concreta no solo en la gestión y formación sobre programas de acción social y voluntariado o desde la faceta investigadora, sino desde la profunda pasión por la participación y su ejercicio práctico y la necesidad sentida de actuar y ser críticos al tiempo como única posibilidad de avanzar realmente.

\section{Referencias}

Alonso, L. E. (1999) "La juventud en el tercer sector: redefinición del bienestar, redefinición de la ciudadanía" Estudios de juventud, 45, 9-20.

Aranz, E. (1990) "Síntesis para un debate abierto" en López de Aguileta, I. (1990) El voluntariado en la acción sociocultural. Madrid: Editorial popular.

Béjar, E. (1995). El ámbito de lo íntimo: privacidad, individualismo y modernidad" Madrid: Alianza Editorial.

Callejo, J. (1999) "Voluntariado estratégico en un contexto no elegido: una hipótesis sobre el creciente acercamiento de los jóvenes a las ONG" Estudios de juventud, 45, 51- 60.

Callejo, J. e Izquieta, J. L. (1996) los nuevos volun- 
tarios: entre el individualismo y la solidaridad. Editorial provincial, Diputación de Valladolid.

Castells, M. (1997) La era de la información. Economía, sociedad y cultura. Madrid: Alianza editorial.

Chacón Rodríguez, L. (1999) "Voluntariado y empleo: desafíos de la (doble) profesionalización” Estudios de juventud, 45, 33-50.

Cortina, A. (1997) "Democracia y movimientos sociales" Temas para el debate, $\mathrm{n}^{\circ} 27$ p. 30-34.

Díez Rodríguez, A. (1999) "Voluntarios, ONGs y sociedad civil en la reordenación globalizadora" Estudios de juventud, 45, 93- 102.

Falcón, E. (1997) Dimensiones políticas del voluntariado: de la promoción al cambio de estructuras. Barcelona: Cristianismo y Justicia.

Fouce, J. G. y Navas, A. B. (1998) Elementos para una crítica constructiva del Voluntariado. $V$ Congreso Estatal Intervención Social. Madrid, 25, 26 y 27 de Noviembre.

Fouce, J. G., Navas, A. B. y Vecina, M (1999) "Voluntariado: imagen social, necesidades, perfil participativo y motivaciones. Un estudio empírico". Revista de Intervención Psicosocial: Igualdad y Calidad de Vida. Colegio Oficial de Psicólogos de Madrid. En prensa.

Fouce, J. G. y Navas, A. B. (1998) Voluntariado y medios de comunicación de masas. II Congreso Iberoamericano Psicología. Madrid, del 13 al 17 Julio 1998.

Fukuyama, F. (1992) El fin de la historia y el último hombre, Editorial Planeta.

Fukuyama, F. (1998) La confianza (Trust). Barcelona: Ediciones B, ÉTNOR: 297.

Fukuyama, F. (2005) "confianza" El País, 2- 92005.

Funes, M. J. (1995) La ilusión solidaria Madrid: UNED.

Funes, M. J. (1997) “Ciudadanía y movimientos sociales: el movimiento urbano al movimiento ciudadano" en Temas para el debate, 27 , 34-40.

Galeano, E. (1992) Ser como ellos y otros artículos. Madrid: Siglo Veintiuno de España Editores.

Galeano, E. (1993) Las palabras andantes, México: Siglo Veintiuno Editores.

GARCÍA ROCA, J. (1994) Solidaridad y voluntariado. Santander: Ed. Sal Terrae.
Gasrcía Márquez (2002) Vivir para contarla. Mondadori España, S.A.

Habermas, J. (1994) "La crisis del Estado de Bienestar y el agotamiento de las energías utópicas". Barcelona: Ensayos Políticos Península.

Huerta de Soto, J. (1996) "Socialismo, Corrup-ción Ética y Economía de Mercado" en Ética Pública y Moral Social Editorial: Noesis, Madrid, 1996 .

Jerez, A. (1999) “Imágenes para pensar los restos de la participación juvenil" Estudios de juventud, $\mathrm{n}^{\circ}$ 45, p. 113-123.

Klanderman, B. (1989) International Social movements research: a research annual Greenwich, Connecticut, Jai Press.

Klanderman, B. (1995) Social movements an cultu e London, UCL press.

Klanderman, B. (1995) The social psichology of protest London, Blackwell.

Klanderman, B., Kriesi, H, and Tarrow, S. (eds) (1988) From Structure to action, comparing social movement research across cultures Greenwich, JAI, Press.

Klanderman, B. (1984): "Mobilization and participation: social-psycoholical expansions of Resource Mobilization Theory". American Sociological Review, 49, 583-560.

Lakoff, G. (2007) "No pienses en un elefante". Editorial complutense, Madrid.

Ley Voluntariado 6/1996 del 15 de enero.

López-Cabanas, M. Y Chacón, F. (1997). Intervención Psicosocial y Servicios Sociales. Un enfoque participativo. Madrid: Ed. Síntesis Psicología.

Madrid, A. (1999) "Participación, voluntariado y desobediencia" Estudios de juventud, 45, 77-85.

Melucci, A. (1989) Nomads of the presents: social movements and individual needs in contemporary society, London, Hutchinson, Philadelphia, Temple University Press.

Melucci, A. (1994) “¿Qué hay de nuevo en los “nuevos movimientos sociales?". En Laraña, E. Y Guisfeld, J. 1994 Los Nuevos Movimientos sociales: de la ideología a la identidad: Madrid: CIS. P.119-149.

Melucci, A. (1996) Challenging codes. Collective action in the informacion age. Cambridge University Press. 
Mendiluce, J. M. (1997) EL amor armado. Barcelona: Planeta.

Petras, J. (1997) "Imperialism and NGOs in Latin America", Monthly Review (Vol.49,No.7), December 1997, New York, 10-27.

Petras, J. (2000) "Las dos caras de las ONGs" http://www.nodo50.org/pchiapas/varios/documentos/petras-ong.htm.

Petras, J. (2006) "el postmarxismo rampante. Una crítica a los intelectuales y las ONGs (y 2)" http://papelesrojos.blogspot.com/2006/05/jamespetras-el-postmarxismo-rampante_08.html

Plan estatal Voluntariado 1997- 2000(1999). Ministerio de Trabajo y Asuntos sociales.

Quintero, Jesús: Cuerda de presos, Ed. Planeta, Barcelona, 1997.

Reincidentes (1998). Disco “Algazara”.

Revilla, M. 1995 "Participación política: lo individual y lo colectivo en el juego de lo político”. En Sociedad y política. Temas de sociología política de Benedicto, J. y Morán, M. L. (eds). Madrid: Alianza Universidad Textos.

Riechman, J. y Fernández Buey, F. (1994). Redes que dan libertad. Barcelona: Paidos.

Savater, F. (1995) "Política para Amador" Editorial Ariel.

Segovia, J. L. (2000) "Neoliberalismo y ONGs: visión critica del voluntariado" Revista Nómadas 2, Madrid: Universidad Complutense.

Segovia, J.L. (2000) "Discernir la "solidaridad": crítica en torno a las "ONGs" y el voluntariado. Éxodo, 54.

Touraine, A. (1997) ¿Podremos vivir juntos? Iguales y diferentes Madrid: Ed. PPC.

Touraine, A. (1998) "De la sociología de los sistemas a la sociología de los actores". Curso magistral en la Universidad Internacional Menéndez Pelayo. Del 7 al 12 de septiembre de 1998.

Velloso de Santisteban, A. (1999) Guía critica del voluntariado en España. Madrid: Espasa Calpe.

Zubero, I. (2000) "Solidaridad y voluntariado en un mundo insolidario". Revista Analitica.com .

Zubero,, I. (1994), Las nuevas condiciones de la solidaridad, Desclée de Brouwer, Bilbao.

Zubero,, I. (2006) "el papel del voluntariado en la sociedad actual”. Boletín unida.

Manuscrito recibido: 18/05/2009

Revisión recibida: 26/08/2009

Manuscrito aceptado: 07/09/2009 